\title{
INFLAMMATORY PSEUDOTUMORS OF THE LUNG: A CLINICAL STUDY OF ELEVEN PATIENTS
}

Salih Topçu, MD, İran Taştepe, MD, Ayşin Alper, MD, Ali Özdülger, MD, Mustafa Albayrak, MD, Durmuş Bozkurt, MD, Tuba Liman, MD, and Güven Çetin, MD, Ankara, Turkey

From the Atatürk Center For Chest Disease and Thoracic Surgery, Department of Thoracic Surgery, Ankara, Turkey.

This study was accepted for presentation in the Annual Congress of European Respiratory Society, Madrid, Spain, October 9-13, 1999.

Received for publication July 14, 1999; accepted for publication Sept 16, 1999.

Address for reprints: Ayşin Alper, MD, Yüksel Caddesi, No: 34/15, Kizılay, 06420, Ankara, Turkey (E-mail: sumena@yahoo.com).

J Thorac Cardiovasc Surg 2000;119:180-2

Copyright $\odot 2000$ by Mosby, Inc.

$0022-5223 / 2000 \$ 12.00+0 \quad \mathbf{1 2 / 5 4 / 1 0 3 0 2 1}$
Inflammatory pseudotumors are rare neoplastic lesions of the lung with unknown etiology. ${ }^{1,2}$ They histologically contain inflammatory and mesenchymal cells and are often confused with carcinomas. Preoperative diagnosis can rarely be established. ${ }^{3}$ The treatment of choice is surgical resection, which has both diagnostic and therapeutic value. ${ }^{1}$ In this study, we report the management of 11 cases of inflammatory pseudotumors in our clinics.

Eleven patients (male/female ratio 10:1, mean age 45.1 years) who had the postoperative diagnosis of pulmonary 
Table I. Surgical procedures in patients with inflammatory pseudotumors of the lung

\begin{tabular}{lrr}
\hline & \multicolumn{2}{c}{ Patients } \\
\cline { 2 - 3 } Surgical procedure & No. & $\%$ \\
\hline Lobectomy & 4 & 37 \\
Pneumonectomy & 2 & 18 \\
Wedge resection & 2 & 18 \\
Segmentectomy & 1 & 9 \\
Biopsy (in resectable cases) & 2 & 18 \\
Total & 11 & \\
\hline
\end{tabular}

inflammatory pseudotumor in our clinics between 1991 and 1997 were included in this study. Exploratory thoracotomy was performed in all patients to establish the exact diagnosis. All of the patients but 1 had symptoms, the most common symptom being cough $(n=9,82 \%)$. Only 3 of the patients had a history of lung disease. In all of the patients, sputum smear showed no abnormalities and cytologic examination of the sputum revealed no atypical cells. The chest x-ray film demonstrated a well-defined pulmonary mass, nodular shadows, or a solitary lesion in 6 patients and ill-defined lesions or infiltrates in the remaining 5 patients, 1 of whom had an intrapulmonary calcification (Fig 1). Bronchoscopic examination did not reveal endobronchial lesions and bronchoalveolar lavage could not disprove the diagnosis of atypical cells in any patients. Stained smears of bronchoalveolar lavage specimens were negative for mycobacteria. Random percutaneous needle biopsy specimens from suggestive areas in 3 of the patients established no diagnosis. The results of scalene node biopsy obtained in 5 of the patients were not diagnostic.

All of the patients underwent exploratory thoracotomy for the definitive diagnosis. Resection was performed in 9 of 11 patients (82\%). The surgical procedures are listed in Table I. Only biopsy tissue was obtained in 2 patients whose lesions were unresectable because of mediastinal invasion. The lesions were right-sided in 8 patients $(73 \%)$, left-sided in 2 $(18 \%)$, and bilateral in 1 patient $(9 \%)$. There was no endobronchial involvement. The postoperative follow-up period ranged from 2 months to 6 years. There were no perioperative deaths, but 2 patients with mediastinal invasion died of respiratory failure 13 and 18 months after the operation. A bronchopleural fistula that developed after a right pneumonectomy was managed with intrathoracic muscle transposition. The rest of the patients remained relapse free for the followup period.

Previous studies report inflammatory pseudotumor to comprise $0.7 \%$ to $1 \%$ of all bronchopulmonary neoplasms. ${ }^{1,2}$ However, it is the most common benign lung tumor in children under 16 years of age. ${ }^{1,2,4}$ Inflammatory pseudotumor, although it can develop at any age, is mostly a disease of young adults. The mean age was 45.1 years in our series with a range of 18 to 65 years. Only a small portion of patients with inflammatory pseudotumor is reported to have symptoms. ${ }^{4}$ In our study group, however, all but 1 patient had

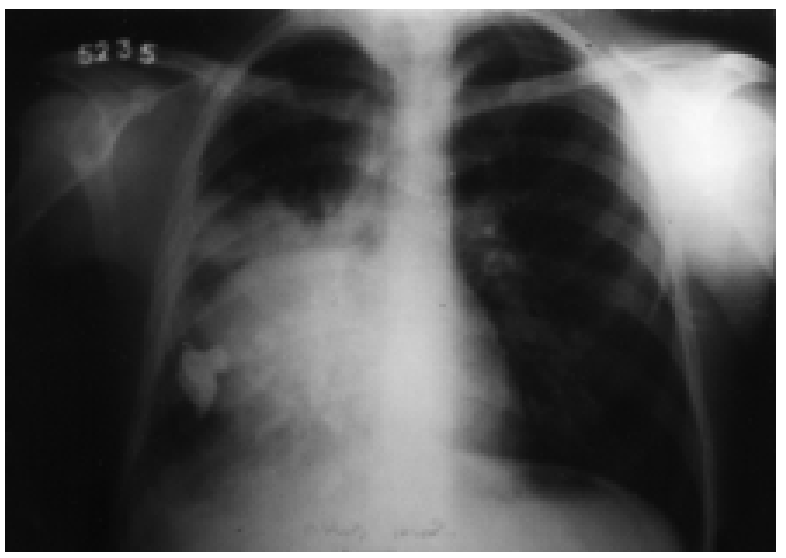

Fig 1. Chest x-ray film demonstrates a pulmonary inflammatory pseudotumor in an 18-year-old man. It represents a welldefined mass that also contains calcification. The mass involves both the middle and lower lobes of the right lung and extends to the hilar region. The patient underwent a right pneumonectomy.

symptoms, although they were mild and nonspecific. Laboratory investigations have no role in the definite diagnosis of inflammatory pseudotumor. Cytologic examination of specimens of sputum and bronchoalveolar lavage will not disprove the diagnosis of malignant cells. ${ }^{2}$ The importance of these methods is to detect an active inflammatory disease such as tuberculosis or malignant neoplasms. However, positive sputum examination for acid-fast bacteria does not exclude the diagnosis of inflammatory pseudotumor. Endobronchial involvement is rare in inflammatory pseudotumor, and it is also difficult to diagnose such involvement by tissue biopsy or percutaneous needle biopsy. ${ }^{2}$ There was no endobronchial involvement in our patients. Radiologic examination is helpful to detect the lesion but nonspecific for the disease. Inflammatory pseudotumor generally represents itself as a solitary pulmonary nodule or mass with welldefined borders. Pulmonary masses with irregular borders, pneumonic infiltrations, consolidations, and atelectasis are rarely seen. ${ }^{2,4}$ Sometimes calcification may be seen. ${ }^{1,2}$ In 2 of our patients the lesions involved the mediastinum; in 1 of them it was bilateral and in the other there was calcification. In the differential diagnosis of inflammatory pseudotumor, sclerosing hemangioma, pseudolymphoma, malignant proliferation of plasma cells, localized organizing pneumonia, and noninfectious granuloma of the lung should be considered.

Surgical resection is the treatment of choice in inflammatory pseudotumor ${ }^{1,4}$ because surgery enables both definitive diagnosis and complete cure. The surgical approach to inflammatory pseudotumor is limited resection. ${ }^{2,5}$ Enucleation is not preferred because of the risk of recurrence. The prognosis is good. The recurrence rate is low in most series. ${ }^{5}$ In our group, complete resection was not possible in 2 patients who had mediastinal involvement, but resection was 
successful in the other $9(83 \%)$ patients, and none of them had a recurrence.

In conclusion, patients who have lung lesions resembling lung carcinoma on chest x-ray films but have negative sputum and bronchoscopic biopsy examinations for malignant cells should be investigated for inflammatory pseudotumor. Exploratory thoracotomy will establish the definitive diagnosis and allow resection in these patients.

\section{REFERENCES}

1. Vujanic GM, Dojcinov D. Inflammatory pseudotumor of the lung in children. Pediatr Hematol Oncol 1991;8:121-9.
2. Ishida T, Oka T, Nishino T, et al. Inflammatory pseudotumor of the lung in adults: radiographic and clinicopathological analysis. Ann Thorac Surg 1989;48:90-5.

3. Doski JJ, Priebe CJ. Corticosteroids in the management of unresected plasma cell granuloma of the lung. J Pediatr Surg 1991; 26:1064-6.

4. Miller JI. Benign tumors of the lower respiratory tract. In: Baue AE, editor. Glenn's thoracic and cardiovascular surgery. ed 6 . New York: Appleton \& Lange; 1996. p. 353.

5. Zeren H, Travis W, Fleming MV, Gal AA, Koss MN. Inflammatory pseudotumors of the lung: a clinicopathological study of 50 cases [abstract]. Mod Pathol 1995;8;156A. 